\title{
PREDICT OF ASPHALT RUTTING POTENTIAL BASED ON IDT AND VALIDATION WITH ANN
}

\section{DIVANDARI Hassan}

Department of Civil Engineering, Nowshahr Branch, Islamic Azad University, Nowshahr, Iran, E-mail: divandari@iauns.ac.ir

Received: 06.08.2019 / Accepted: 30.09.2019/ Revised: 30.10.2019 / Available online: 10.12.2019

DOI: 10.2478/jaes-2019-0018

KEY WORDS: IDT, Rut Depth, Vertical Deformation, Artificial Neural Network.

\begin{abstract}
:
Rutting occurs due to accumulation of incrementally small permanent deformations from each load application and it can cause irreparable problems in pavements. On the other hand, the Marshall Mix design which is known as the main method in Iran, the lack of a simple test to determine specimen resistance to permanent deformation as the major reason for asphalt rutting is noticeable. Although today many devices are used for rutting measurement, none of them have the ability to use in wider field. In addition, prevalent methods of evaluating rutting potential are usually costly and time consuming. Mentioned parameters illustrate the necessity of developing a simple method, not only having fine precision, but also are able to predict rutting performance with low cost in the short term in laboratory. In this research, after performing the main tests on specimens, IDT test results and Marshall Parameters were used to develop a mathematical model to estimate specimen rut depth. The model is validated by using ANN and makes it possible to evaluate mixtures rutting potential while OBC is being determined in laboratory. So not only is there no need to use expensive instruments of rutting test, but also a remarkable time saving in mix design procedure is achievable.
\end{abstract}

\section{INTRODUCTION}

Rutting is one of the major distress mechanisms in flexible pavements. Because of the increase in tire pressure and axle loads in recent years, rutting has become the dominant mode of failure of flexible pavements in many countries (Al-Khateeb et al. 2018, Radhakrishnan et al. 2019). Rutting is a longitudinal surface depression in the wheel path accompanied, in most cases, by pavement upheaval along the sides of the rut. Significant rutting can lead to major structural failure and reduces serviceability and creates the hazard of hydroplaning because of accumulated water in the wheel path ruts, which is a safety hazard (Mamlouk et al. 2018, Wang et al. 2017).

\subsection{Problem Definition}

Generally, there are three causes of rutting in asphalt pavements: Permanent reduction in mixture volume (subgrade consolidation), Permanent movement of the material at constant volume (plastic deformation), and wear of pavements caused by studded tires and car chains (surface layer abrasion). In addition, a combination of the first and second reasons could be the cause of rutting (Mamlouk et al. 2018). Nevertheless, the Surface permanent deformations have the most shares among various rutting causes ((TRI) 2010). In the past, subgrade deformation was considered to be the primary cause of rutting and many pavement design methods applied a limiting criterion on vertical strain at the subgrade level. However, recent research indicates that most of the rutting occurs in the upper part of the asphalt surfacing layer, so considering it in mix design procedure seems essential (Mamlouk et al. 2018, Du et al. 2018). The rate and magnitude of rutting depend on external and internal factors. External factors include load and volume of truck traffic, tire pressure, temperature, construction practices and compaction. Internal factors include properties of the binder, the aggregate and mix properties, and the thickness of the pavement layers. Rehabilitation of rutted pavement usually involve asphalt concrete (AC) overlay, recycling, or replacement of all structural layers (Mamlouk et al. 2018, Ziari et al. 2019). Different researches used various methods to evaluate asphalt mixtures rutting potential.
Dynamic creep test is used widely in Finland, Sweden and Australia while LCPC1 wheel trucker is used more in Austria, France, Hungary, Romania and Switzerland. Hamburg Wheel Tracking Device and Georgia Loaded Wheel Tester are used for rutting performance evaluation in many countries in the world (Ziari and Divandari 2013). Wheel Trucker applies wheel cyclic load to the specimen and the rut depth is recorded after 8000 cycles in a specific temperature. It is proofed that rut depth is related to specimen shear strength inversely. Although it is a simple test, it is time consuming and the instrument used for loading is expensive. So developing a method to determine asphalt mixture shear strength in less time with cheaper equipment seems necessary (Ziari et al. 2012).

\subsection{Rutting Mechanisms}

Rutting types and mechanisms of its occurrence can be classified as follows:

Rutting due to bottom layers' consolidation (weak subgrade): This phenomenon usually occurs in the early life of the pavement due to layers' congestion caused by heavy traffic (Liao, Wang, and Shi 2018). The main cause of this type of rutting is the weakness of underlying base or subgrade layers (Mamlouk et al. 2018). Such rutting is usually wide and has a width of 0.75 to 1.0 meter. The other characteristics of this type of rutting are $\mathrm{V}$ shaped section with low depth and without crack. According to figure 1, in this rutting, against the thickness of asphalt layers that remained relatively constant, the thickness of bottom layer is changed (Mamlouk et al. 2018, Du et al. 2018).

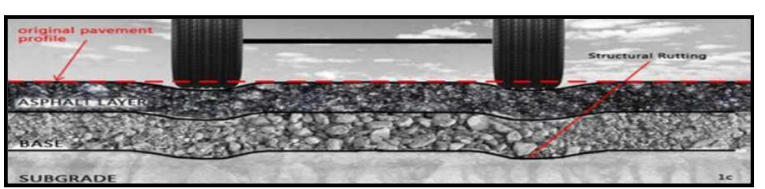

Figure 1. Rutting due to bottom layers consolidation (weak subgrade) (Inzerillo et al. 1995) 
Rutting in asphalt layer due to lack of shear strength: This type of failure is resulting due to displacement or lateral movement of material in effect of cutting from the vehicles tire and essentially caused by the lack of shear strength in asphalt layer. This rutting has $\mathrm{W}$ shaped section by smooth surface and usually one or more boundary formed at the bottom of this rut and in the space between the wheels by small bumps. As shown in figure 2, Shear deformation occurs with no change in volume, reduction volume of pavements material under the tires is approximately equal with the increased volume of the raised lateral areas.

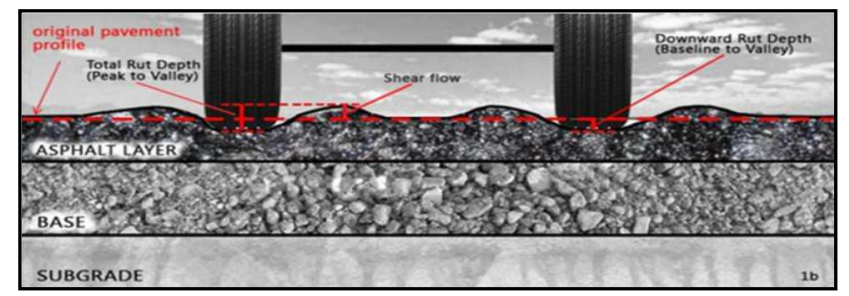

Figure 2. Rutting in asphalt layer due to lack of shear strength (Inzerillo et al. 1995)

Rutting due to studded tire wear (surface layer abrasion): This type of rutting is caused by ribbed tires motion (with studded tire and chains) on pavement in winter and the major reason of its creation is weak resistance of asphalt mixtures. Figure 3 illustrates rut depth is measured in the deepest part of the rutting by ruler and screed.

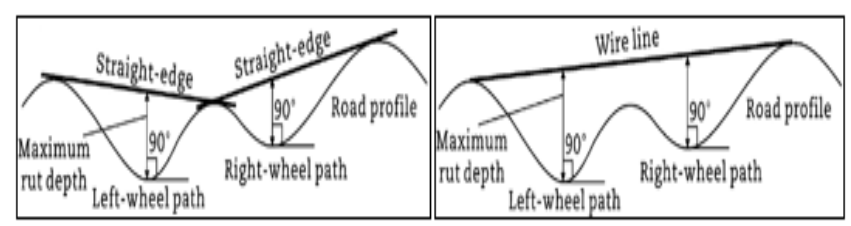

Figure 3. Rut depth measurement (Wang et al. 2017)

\subsection{Research Subject Importance}

In recent years, increasing intensity and expanse of permanent deformation create concerns about the effect of this failure on the asphalt pavements performance. This deterioration reduces serviceability and increases the effects of moisture and freezing hazard due to hydroplaning in the wheel path rutting. In addition, this phenomenon causes bleeding, during that bitumen rises to pavements surface and by reducing friction can lead to traffic accidents (Ziari and Divandari 2013, Zhang et al. 2019, Shafabakhsh et al. 2018). The other effects of rutting are the pavement drainage capacity reduction, make moisture based deterioration growing rate faster, pavement thickness decrease in rutted zone and finally increase fatigue cracking in flexible pavements (Zhang et al. 2019, Al-Khateeb et al. 2018). Mentioned parameters introduce rutting as an expensive flexible pavement deterioration mechanism (Ziari and Divandari 2013, Yi, Wang, and Zhou 2011). On the other hand, the Marshall mix design which is known as the main method of asphalt mix design in Iran, the lack of a simple test to determine specimen resistance to permanent deformation as the major reason for asphalt rutting is noticeable (Ziari et al. 2012). Although today many devices used for rutting measurement, none of them have the ability to be used in wider field. In addition, prevalent methods of evaluating rutting potential of asphalt mixtures are usually expensive and time consuming. Mentioned parameters illustrate the necessity of developing a simple method, not only having fine precision but also, are able to predict specimens rutting performance with low cost in the short term in laboratory.

\subsection{Literature Review}

Lack of a simple test to evaluate asphalt mixtures performance caused validated research centers such as NCHRP2, FHWA3, FAA4 and State Highway Agencies to sponsor projects with the objective of developing test methods and procedures which can be readily implemented to evaluate the rutting potential of mixtures (McGarvey et al. 2010, Parsons, Kazmee, and Garg 2017). Several projects were initiated by the NCHRP to study the issue of a simple performance test for permanent deformation evaluation of asphalt mixtures. One of these projects, NCHRP Project 9-16, examined the use of properties available from the SUPERPAVE gyratory compactor (SGC) during the compaction process. The research was based on the hypothesis that some property of the asphalt mixture available during compaction in the SGC was related to the rutting resistance of the mix. The research found that properties during SGC compaction, such as compaction slope (K), appeared to be somewhat related to aggregate characteristics (gradation, particle shape or texture and angularity) but, were insensitive to asphalt binder characteristics such as asphalt binder content and grade (stiffness) (Anderson 2002).

In a separate study of simple performance testing, the Pennsylvania Transportation Institute (PTI) and Advanced Asphalt Technologies (AAT) discovered that the indirect tensile strength of an asphalt mixture was related to mixture cohesion in the Mohr-Coulomb failure theory and thus according to equation 1 was related to rutting potential:

$$
\tau=\sigma \tan (f)+c
$$

where:

$\tau$ is Shear Stress $(\mathrm{K} . \mathrm{Pa}), \sigma$ is Normal Stress $(\mathrm{K} . \mathrm{Pa}), \mathrm{C}$ is Cohesion (K. Pa) and $\mathrm{f}$ is Angel of Internal Friction (degrees).

Anderson in 2002 applied the Mohr-Coulomb theory of material behavior to the evaluation of the rutting potential of HMA5 (Anderson 2002). Also Anderson et al in 2003, examines the use of indirect tensile strength (IDT), volumetric parameters such as voids in mineral aggregate (VMA) and SUPERPAVE Gyratory Compaction (SGC) properties to predict rutting potential of an asphalt mixture. In this research, indirect tensile strength was the indicator of cohesion and compaction slope parameter was the indicator of the internal friction of asphalt mixtures (Anderson, Christensen, and Bonaquist 2003). Following Anderson's laboratory research about evaluate rutting potential of asphalt mixtures, the new research similar to Anderson's principles and methods, but with a little difference created by Zaniewski and Srinivasan in 2004. This research was based on the hypothesis that the rutting potential of asphalt mixtures evaluated from APA6 is governed by three main parameters, compaction slope, VMA and IDT strength (Zaniewski and Srinivasan 2004). The major difference between these researches was the equipment and devices that used for evaluating asphalt mixtures rutting. Anderson used $\mathrm{RSCH} 7$ to estimate the rutting potential, which is sophisticated and expensive, but in recent researches used APA. APA is widely available in the industry for evaluating the rutting potential of asphalt mixtures. The main target of this research was examined the use of using indirect tensile strength test to predict rutting potential of HMA and extend Anderson's work to use simple tests and equipment readily available in industry and field level of Iran.

\section{RESEARCH TARGETS \& ASSUMPTIONS}

\subsection{Research Targets}

According to Anderson's research in 2003 which provides a simple method for the evaluation of asphalt mixtures rutting, an important point to be noted in this context is that the tools and equipment that used by Anderson for evaluating asphalt mixtures rutting are not readily available in industry and field level especially in Iran. 
Therefore, the main point of this research was to examine the use of indirect usage tensile strength test and Marshall Parameters to predict rutting potential of hot asphalt mixtures and extend Anderson's work to use simple tests and equipment readily available in industry and field level of Iran. The presented model measuring mixture rutting resistance by using the combination of indirect tensile strength test results and Marshall Parameters. With this assumption that indirect tensile strength was the indicator of cohesion and Marshall Parameters was the indicator of the internal friction of asphalt mixtures. The model is validated by using Artificial Neural Network and made it possible to evaluate mixture rutting potential while optimum asphalt content is being determined in laboratory. So not only is there no need to use expensive instruments of rutting test but a remarkable time saving in mix design procedure is achievable.

\subsection{Research assumption}

In addition to the general assumptions that will be discussed in their turn, the main assumption is that the combination of indirect tensile strength test results and Marshall Parameters could be considered a suitable criterion for evaluating rutting of asphalt mixture specimens. This parameter was studied in this research under $40^{\circ} \mathrm{C}$ temperature. Also two variables are used to enhance the application of research results that include: Bitumen Type and Different Bitumen Content.

\section{METHODOLOGY AND MATERIAL SELECTION}

Materials used in this research included: one type of aggregate (calcareous aggregates), one type of gradation (gradation number 4), two types of bitumen (bitumen grade 60-70 \& 85-100), and one type of filler (rock powder), which all of them are Iran internal productions. Calcareous aggregates used as consumption aggregate is a sample of Tehran-Chalous Freeway project ( $21 \& 22$ Section) and selected in different sizes of sand $(0 \mathrm{~mm}-6 \mathrm{~mm})$, fine gravel $(6 \mathrm{~mm}-12 \mathrm{~mm})$, and medium gravel $(12 \mathrm{~mm}-19 \mathrm{~mm})$. Nowshahr mine rock powder passed from $0.075 \mathrm{~mm}$ sieve was used as filler in specimen preparation procedure. PI and Hydrometric test results located in standard range either. Bitumen was supplied from Pasargad Oil Company in two types of 60-70 and 85-100.

\subsection{Aggregates gradation}

Among the various proposed gradation in code 234 (Iran Highway Asphalt Paving Code, 2011), middle range of number 4 continuous gradations were used in this research according to table 1 and also figure 4 .
Table 1. Aggregates gradation for to pka layer

\begin{tabular}{|c|c|c|c|c|c|}
\hline \multicolumn{3}{|c|}{ Sieve Specification } & \multicolumn{3}{|c|}{ Number 4 Continuous Gradation } \\
\hline \multicolumn{3}{|c|}{ Sieve } & $\begin{array}{l}\text { Passed } \\
\text { Range }\end{array}$ & Passed & Remained \\
\hline $\mathrm{mm}$ & Number & Inches & $\begin{array}{c}\text { Weight } \\
(\%)\end{array}$ & $\begin{array}{c}\text { Average } \\
\text { Weight } \\
(\%)\end{array}$ & $\begin{array}{c}\text { Weight } \\
(\%)\end{array}$ \\
\hline 19 & - & $(3 / 4)$ & 100 & 100 & 0 \\
\hline 12.5 & - & $(1 / 2)$ & $90-100$ & 95 & 5 \\
\hline 9.5 & - & $(3 / 8)$ & - & - & - \\
\hline 4.75 & 4 & - & $44-74$ & 59 & 36 \\
\hline 2.36 & 8 & - & $28-58$ & 43 & 16 \\
\hline 1.18 & 16 & - & - & - & - \\
\hline 0.6 & 30 & - & - & - & - \\
\hline 0.3 & 50 & - & $5-21$ & 13 & 30 \\
\hline 0.15 & 100 & - & - & - & - \\
\hline 0.075 & 200 & - & $2-10$ & 6 & 7 \\
\hline
\end{tabular}

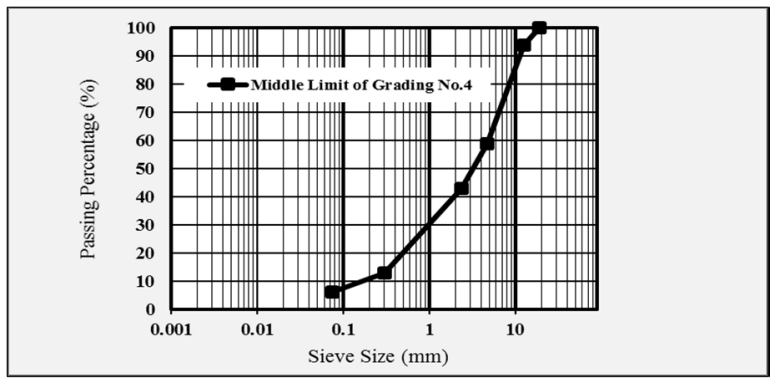

Figure 4. Graph of Middle Limit of Grading No.4

\subsection{Aggregate quality tests}

As shown in table 2, to evaluate the quality of aggregates performed Los Angeles Abrasion, Elongation Index \& Flakiness Index, Fracture Percentage of Aggregate, Sand Equivalent, Aggregate Resistance against Sodium Sulfate Tests and the test results are in the standard range.

Table 2. Aggregate quality tests results

\begin{tabular}{|c|c|c|c|c|c|c|}
\hline \multirow[b]{2}{*}{ Aggregate Tests } & \multirow[b]{2}{*}{ Characteristic } & \multirow[b]{2}{*}{ Tests Standards } & \multicolumn{2}{|c|}{ Test Results } & \multicolumn{2}{|c|}{$\begin{array}{l}\text { Allowable Value for Surface } \\
\text { Layer }\end{array}$} \\
\hline & & & $\begin{array}{c}\text { Coarse } \\
\text { Aggregate }\end{array}$ & $\begin{array}{c}\text { Fine } \\
\text { Aggregate } \\
\text { (Sand) }\end{array}$ & $\begin{array}{c}\text { Coarse } \\
\text { Aggregate }\end{array}$ & $\begin{array}{c}\text { Fine } \\
\text { Aggregate } \\
\text { (Sand) }\end{array}$ \\
\hline \multirow{3}{*}{ Los Angeles Abrasion Test } & Gradation Type & \multirow{3}{*}{ AASHTO-T96 } & B & - & - & - \\
\hline & Number of Round & & 500 & - & - & - \\
\hline & Abrasion Percentage & & 16 & - & Max 30 & - \\
\hline \multirow{2}{*}{$\begin{array}{l}\text { Elongation Index \& Flakiness } \\
\text { Index }\end{array}$} & Elongation & \multirow{2}{*}{ BS-812 } & 7 & - & - & - \\
\hline & Flakiness & & 18 & - & Max 25 & - \\
\hline Fracture Percentage of & On Two Fronts & ASTM-D5821 & 95 & - & Min 90 & - \\
\hline Sand Equivalent Test (S.E.) & - & AASHTO-T176 & - & 56 & - & Min 50 \\
\hline \multirow{2}{*}{$\begin{array}{l}\text { Aggregate Resistance against } \\
\text { Sodium Sulfate }\end{array}$} & Fine Aggregate & \multirow{2}{*}{ AASHTO-T104 } & - & 3.4 & $\operatorname{Max} 8$ & - \\
\hline & Coarse Aggregate & & 1.2 & - & - & Max 12 \\
\hline
\end{tabular}


Table 3. Bitumen's tests results

\begin{tabular}{|c|c|c|c|c|c|c|c|c|}
\hline \multirow[t]{2}{*}{ Bitumen's Tests } & \multicolumn{2}{|c|}{ Tests Standards } & \multirow{2}{*}{$\begin{array}{c}\text { Bitumen } \\
\text { Grade 60-70 } \\
\text { Results }\end{array}$} & \multicolumn{2}{|c|}{$\begin{array}{l}\text { Allowable Range } \\
\text { of } 60-70\end{array}$} & \multirow{2}{*}{$\begin{array}{l}\text { Bitumen } \\
\text { Grade 85- } \\
\text { 100 Results }\end{array}$} & \multicolumn{2}{|c|}{ Allowable Range of $\quad 85-100$} \\
\hline & AASHTO & ASTM & & Min & Max & & Min & $\operatorname{Max}$ \\
\hline Specific Gravity & T228 & D70 & 1.011 & - & - & 1.008 & - & - \\
\hline Penetration Grade & T49 & D5 & 63 & 60 & 70 & 88 & 85 & 100 \\
\hline Softening Point & T53 & D36 & 51 & 49 & 56 & 48 & 45 & 52 \\
\hline Ductility & T51 & D113 & $100+$ & 100 & - & $100+$ & 100 & - \\
\hline Flash Point & $\mathrm{T} 48$ & D92 & 305 & 232 & - & 298 & 232 & - \\
\hline Viscosity & $\mathrm{T} 201$ & D2170 & 341 & - & - & 259 & - & - \\
\hline Solubility of Bituminous & T44 & D2042 & 99.72 & 99 & - & 99.85 & 99 & - \\
\hline Thin Film Over Test & T179 & D1754 & 0.04 & - & 0.8 & 0.06 & - & 1 \\
\hline
\end{tabular}

\subsection{Bitumen's tests}

Table 3 illustrates Specific Gravity, Penetration Grade, Softening Point, Ductility, Flash Point, Viscosity, Solubility of Bituminous, Thin Film Over Tests performed for both types and results passed Code 234 (Code 2011).

\subsection{Preparation asphalt mixture specimens}

In this research, used Marshall Mix design method based on the ASTM-D1559 standard to make asphalt mixture specimens and the compaction operation performed by Marshall Compaction hammer with 75 stroke to each side of the cylindrical specimen.

Optimum Bitumen Content Determination: According to this study, that used the middle limit of gradation No.4 and two types of asphalt cement for preparing the specimens, this research has two types of Asphalt Mixture Combination (AMC):

a. Type (1) of Asphalt Mixture Combination: with the middle limit of gradation No.4 \& bitumen grade 85-100;

b. Type (2) of Asphalt Mixture Combination: with the middle limit of gradation No.4 \& bitumen grade 60-70.

For each asphalt mixture combination, three groups of asphalt mixture specimens with the percentages of bitumen $4 \%, 4.5 \%, 5 \%$, $5.5 \%, 6 \%$ and $6.5 \%$ and in total 36 specimens were prepared for $\mathrm{OBC}$ and finally two optimum bitumen contents were determined as mentioned in table 4.

Table 4. Determined OBC for 2 various asphalt mixture combinations (AMC)

\begin{tabular}{|l|l|l|}
\hline Asphalt Mixture Combination Type & AMC (1) & AMC (2) \\
\hline Optimum Bitumen Content (OBC) & $5.3 \%$ & $5.5 \%$ \\
\hline
\end{tabular}

\subsection{Preparation main specimens for tests}

To make main specimens, due to various variables, 54 specimens were prepared totally with $\mathrm{OBC}, 0.5 \%$ less and $0.5 \%$ more bitumen content as shown in figure 5 . To validate test results 3 specimens were made for each similar condition. This research used three main tests for evaluation asphalt specimen's performance: Marshall, Indirect Tensile Strength and, Wheel Track.

\subsection{Determining number of specimens for research}

According to various variables, exactly 90 specimens were prepared totally with $\mathrm{OBC}, 0.5 \%$ less and $0.5 \%$ more bitumen content with Marshall Method.

\section{RESEARCH MAIN TESTS DEFINITION}

\subsection{Wheel track test}

Wheel Track test directly used for measuring rutting of compacted asphalt mixture. Prepared cylindrical specimens with Marshall Compactor or gyratory compactor placed under the loading wheel until 700 (k.pa) pressures. Rutting test was performed for each specimen in $40^{\circ} \mathrm{C}$ and 60 loads per second as loading rate and the rut depth after 8000 cycles were recorded.

\subsection{Indirect tensile strength test}

Indirect tensile strength test uses for tensile strength evaluation and also prediction cracks in the asphalt mixtures. In addition, IDT test assesses moisture sensitivity and fatigue life of asphalt specimens. IDT performance method bases on the ASTM-D4321 standard. This research used Marshall Stability device and modified loading frame for evaluating tensile strength of specimens. As shown in figure 6, loading application is linear. Also loading speed in this test is 50 $\mathrm{mm} / \mathrm{min}$.

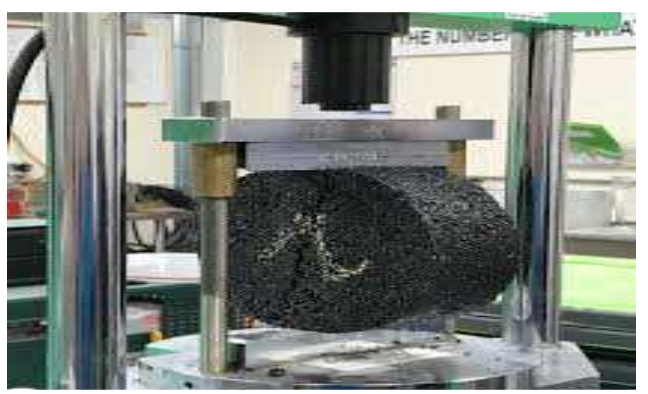

Figure 5. Modified Loading Frame of ID Test

\subsection{Tests results and analysis}

The results of Marshall, Rice, Indirect Tensile Strength, and Wheel Track tests are in next page on table 5.

\subsection{Preparing laboratory model}

Developing a Model Using SPSS8.20 Predicting a variable behavior by using other variable behaviors is the target of regression. It orders to recognize the relation between effective parameters $(x)$ and affected parameters (y) and to ensure a meaningful correlation between variables and finally to estimate a variable, we need $\left(\mathrm{R}^{2}\right)$. Correlation Coefficient $\left(R^{2}\right)$ is a parameter which illustrates a relation between model results and actual results. Two assumptions are considered in regression as $\mathrm{H} 0$ and $\mathrm{H} 1$ :

$\mathrm{H} 0: \mathrm{R}=0$

$\mathrm{H} 1: \mathrm{R} \neq 0$ 
Table 5. The main tests results for 72 specimens "A.M.C (1) \& (2)"

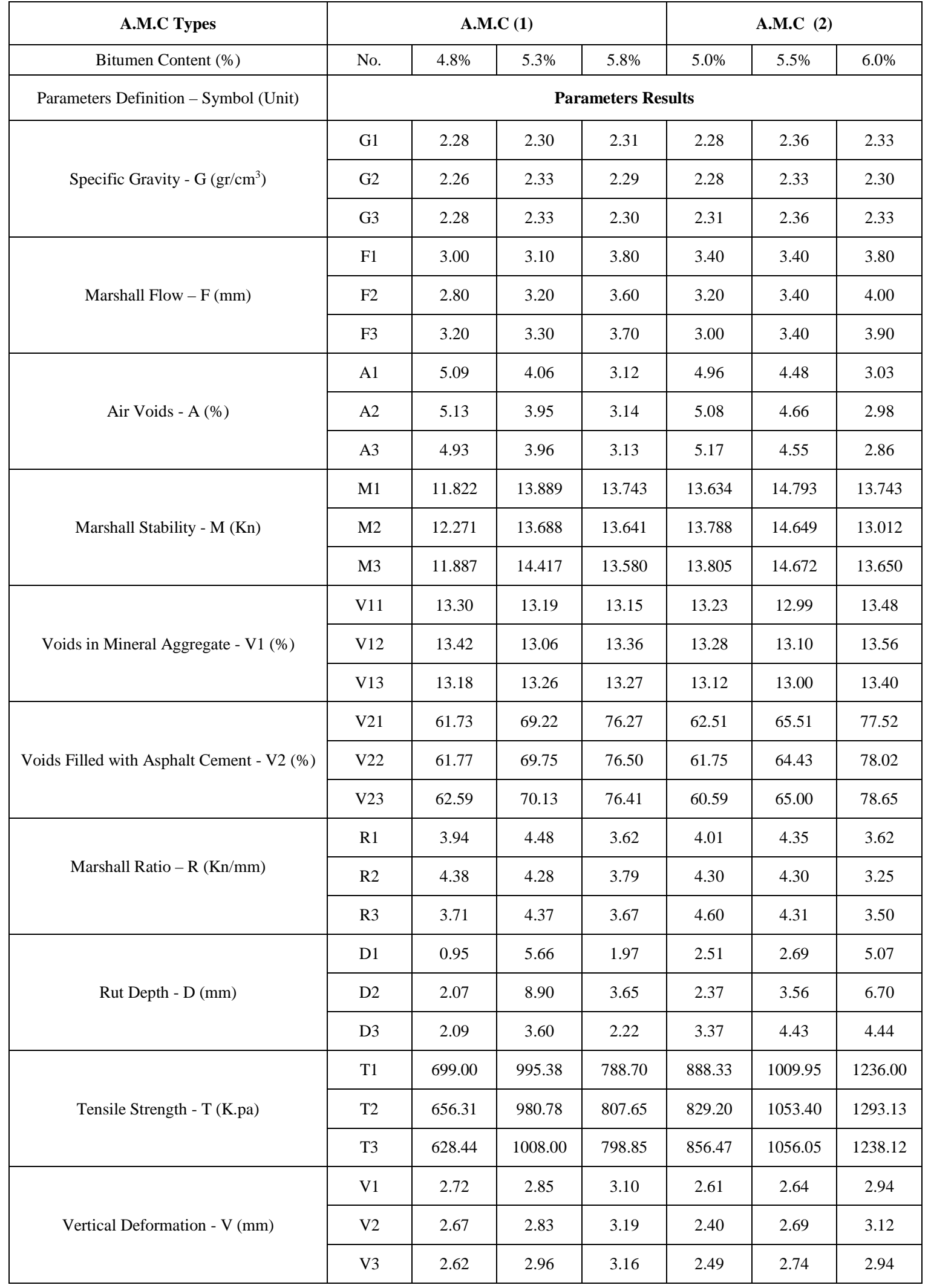

The aim is to reject $\mathrm{H} 0$ assumption which sig $\mathrm{F}$ change coefficient is used for validation. Whatever this coefficient is less, $\mathrm{R}^{2}$ meaningfulness is more and so the model is more validated. This coefficient should be less than 0.05 since reliability is considered as $95 \%$ in this model (Ziari and Divandari 2013). Statistical analysis results of 72 data series in SPSS is listed in table 6.

According to tables 7, 8 and 9, final model was presented as equation 3:

$\mathrm{D}=0.003 \mathrm{~T}+2.737+2.951 \mathrm{~V}-0.736 \mathrm{M}$ 
In which: D is Rut Depth from Wheel Tracker Test (mm), V is Vertical Deformation from Indirect Tensile Strength Test (mm), M is Marshall Stability (Kn), T is Indirect Tensile Strength of IDT Test (K.pa).

Table 6. Parameters statistical analysis in SPSS results

\begin{tabular}{|c|c|c|c|c|c|}
\hline & $\mathrm{N}$ & Minimum & Maximum & Mean & $\begin{array}{c}\text { Std. } \\
\text { Deviation }\end{array}$ \\
\hline $\mathrm{D}$ & 24 & 0.95 & 8.90 & 3.5417 & 1.45871 \\
$\mathrm{M}$ & 24 & 11.822 & 17.303 & 14.3603 & 1.1925 \\
$\mathrm{~T}$ & 24 & 628.44 & 1423.68 & 1106.675 & 179.58062 \\
$\mathrm{~V}$ & 24 & 2.36 & 3.19 & 2.6525 & 0.24451 \\
\hline
\end{tabular}

Table 7. Model statistical specification summary

\begin{tabular}{|c|c|c|c|c|c|}
\hline Model & $\mathrm{R}$ & $\begin{array}{c}\mathrm{R} \\
\text { Square }\end{array}$ & $\begin{array}{c}\text { Adjusted } \\
\text { R Square }\end{array}$ & $\begin{array}{c}\text { Std. Error of } \\
\text { the Estimate }\end{array}$ & $\begin{array}{c}\text { Durbin- } \\
\text { Watson }\end{array}$ \\
\hline 1 & $.962^{\mathrm{a}}$ & .925 & .896 & .46953 & 1.077 \\
\hline
\end{tabular}

a. Predictors: (Constant), V, M, T

As it can be understood from table 7, $\mathrm{R}$ for this model is 0.962 which is meaningful in $95 \%$ reliability level.

Table 8. Analysis of variance (SPSS output) ${ }^{\mathrm{a}}$

\begin{tabular}{|c|c|c|c|c|c|c|}
\hline \multicolumn{2}{|c|}{ Model } & Sum of Squares & $\mathrm{df}$ & $\begin{array}{c}\text { Mean } \\
\text { Square }\end{array}$ & F & Sig. \\
\hline 1 & Regression & 21.643 & 3 & 7.214 & 32.72 & $.000^{\mathrm{b}}$ \\
& Residual & 1.764 & 8 & .220 & 4 & \\
\hline & Total & 23.406 & 11 & & & \\
\hline
\end{tabular}

a. Dependent Variable: D

b. Predictors: (Constant), V, M, T

Table 9. Model independent variables coefficient

\begin{tabular}{|c|c|c|c|c|c|c|c|}
\hline \multirow{2}{*}{$\frac{\overline{0}}{\bar{c}}$} & \multicolumn{2}{|c|}{$\begin{array}{c}\text { Un } \\
\text { standardized } \\
\text { Coefficients }\end{array}$} & \multirow{2}{*}{\begin{tabular}{|c|}
$\begin{array}{c}\text { Standardized } \\
\text { Coefficients }\end{array}$ \\
Beta \\
\end{tabular}} & \multirow[t]{2}{*}{$\mathrm{t}$} & \multirow[t]{2}{*}{ Sig. } & \multicolumn{2}{|c|}{$\begin{array}{c}95.0 \% \\
\text { Confidence } \\
\text { Interval for B }\end{array}$} \\
\hline & B & $\begin{array}{c}\text { Std. } \\
\text { Error }\end{array}$ & & & & \begin{tabular}{|l|} 
Lower \\
Bound
\end{tabular} & $\begin{array}{l}\text { Upper } \\
\text { Bound } \\
\end{array}$ \\
\hline (Cons.) & 2.737 & 3.13 & & .874 & 407 & -4.483 & 9.957 \\
\hline V & 2.9 & .7 & .45 & & .00 & 1.308 & 4.593 \\
\hline M & -.736 & .152 & -.6 & -4. & .001 & -1.087 & -.385 \\
\hline $\mathrm{T}$ & .003 & .001 & .390 & 3.345 & .010 & .001 & .005 \\
\hline
\end{tabular}

\subsection{Validating the model using ann ${ }^{9}$}

ANN is a simulation of brain nerve and learns, generalization, and decision making power like human's brain. In designing the network, after defining a dynamic the system mechanism, the model is trained and system mechanism is saved in model memory, so this memory is used to estimate new cases. Neural networks have been used in various aspects of pavement engineering such as estimating asphalt dynamic and elasticity modulus (Mansourian, Ghanizadeh, and Golchin 2019, Kaya et al. 2018), asphalt cement properties effect on asphalt features (Gu et al. 2018), fatigue cracking prediction (Gong et al. 2019), and Mixture Compaction Quality Control (Barman et al. 2018). A neural network is composed from several processors which are called neurons or nodes.

Each neuron connected to other neurons with oriented lines has specific weight. Weight shows the amount of information used by network to solve the problem. Neurons are organized in groups called layers. Generally, there are two layers, input layer (to get input data) and output layer (to transfer answers out of network). Other layers between these two layers are called hidden layers. Network input and output layer number depends on dependent and independent variables of the desired relation respectively. The model in this paper has two independent variables and one dependent variable, so the network has two input neurons and one output neuron (figure 6). Figure 7 shows input (I) and output (O) and a hidden neuron structure. $\mathrm{B}$ and $\mathrm{W}$ parameters could be set up and $\mathrm{F}$ function type is selected by designer so the neuron output is desired. Determining B and W for total network is called network training. Network output is compared with actual observations and error is calculated in training process. Coefficients are modified based on this error. Whatever roots mean square error (RMSE) is closer to zero, error is less, so the model is better (Ziari and Divandari 2013).

$$
R M S E=\sqrt{\frac{\sum_{i=1}^{n}\left(x_{i}-y_{i}\right)^{2}}{n}}
$$

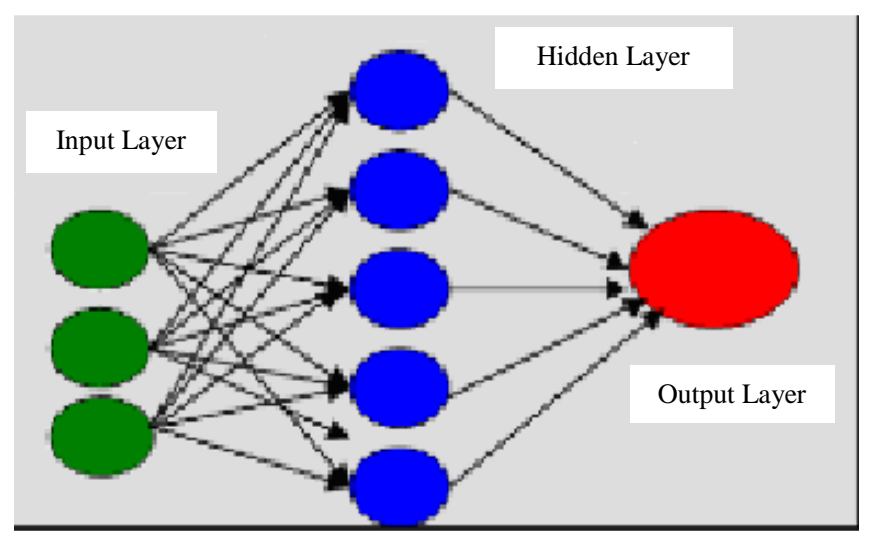

Figure 6. ANN Layers

$\mathrm{R}^{2}$ is the statistical index to validate output accuracy which whatever closer to 1, more precise the model is: (Ziari and Divandari 2013)

$$
R^{2}=\left(\frac{\left(x_{i}-\bar{x}\right)\left(y_{i}-\bar{y}\right)}{\sqrt{\left(x_{i}-\bar{x}\right)^{2}\left(y_{i}-\bar{y}\right)^{2}}}\right)^{2}
$$

MATLAB 2013 software was use for coding the network. About $70 \%$ of data were used for training the network after normalizing by equation 10 and remained data were used for validation.

$$
\mathrm{X} n=(\mathrm{x}-\mathrm{x} \min ) /(\mathrm{x} \max -\mathrm{x} \min ), \quad 0 \leq \mathrm{Xn} \leq 1
$$

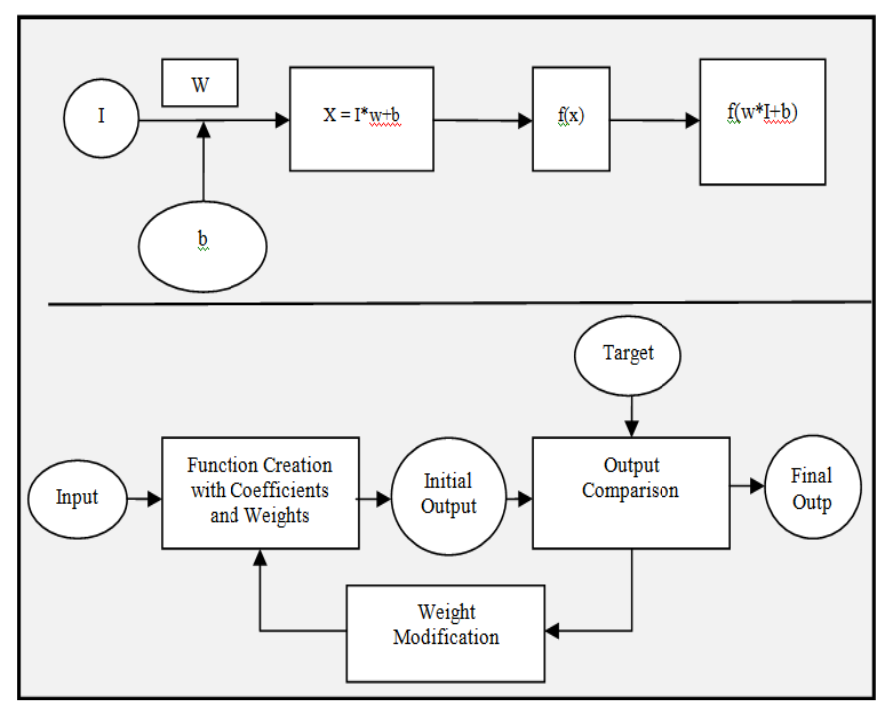

Figure 7. Neural Network Architecture 


\subsection{Neural network results for presented model}

Considering three neurons in input layer, one in output and using 5, 15 , and 30 neurons in median layers, the results were obtained as figure 8 . $R^{2}$ were determined as 0.9835 in best structure in validation phase as it is stated in table 10 .

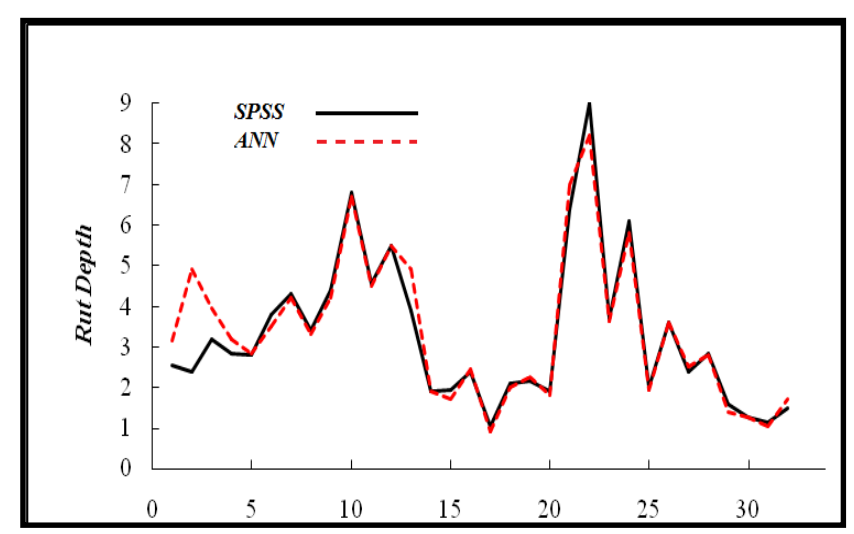

Figure 8. Rut Depth Curve of Model and Real Values

Table 10. Neural network runs output

\begin{tabular}{|c|c|c|c|}
\hline \multirow{2}{*}{$\begin{array}{l}\text { Neural Network } \\
\text { Structure }\end{array}$} & \multicolumn{2}{|c|}{ Training Phase } & \multirow{2}{*}{$\frac{\text { Validation Phase }}{\mathrm{R}^{2}}$} \\
\hline & $\mathrm{R}^{2}$ & RMSE & \\
\hline $3-5-1$ & 0.7963 & 0.0105 & 0.6688 \\
\hline $3-15-1$ & 0.8977 & 0.0118 & 0.8025 \\
\hline $3-30-1$ & 0.9919 & 0.00926 & 0.9835 \\
\hline
\end{tabular}

\section{DISCUSSION AND CONCLUSION}

This research was based on the hypothesis that the rutting potential of asphalt mixtures evaluated from Wheel Track Tester is governed by indirect tensile strength test results and Marshall Parameters. All the eight predictor variables considered in this research had a significant effect on rutting potential. Statistical models were developed to evaluate the relationship of rut depth with these eight independent variables, but the best model statistically was the one that correlated rut depth with IDT strength and vertical deformation resulted from IDT test that used Marshall Stabilometer with a modified loading frame, and Marshall Stability resulted from Marshall Stabilometer test. In continue, according to statistical analysis and related tables, the results can be expressed as follows:

\subsection{The Results of Optimum Bitumen Content Determination for Two Types of Asphalt Mixture Combinations}

- According to table 4 , the optimum bitumen content of specimens made by bitumen grade 60-70 (AMC 2) was about $0.2 \%$ more than the specimens prepared with bitumen grade 85-100 (AMC 1). The reason of this issue can be the high coverage power of bitumen grade 85-100.

5.2 The results of independent variables effect on dependent variable (rut depth)

- Table 5 illustrated that the Marshall Parameters results of specimens that made by bitumen grade 60-70 (AMC 2), except the two volumetric parameters (VMA \& VFA), were more than the specimens prepared with bitumen grade 85-100 (AMC 1).

- As shown in table 5, indirect tensile strength (T) and vertical deformation (V) resulted from IDT test used Marshall Stabilometer with a modified loading frame. These two parameters had a substantially effect on rutting potential and was selected as an independent variable for the rut depth final model.

- According to achieved results, Wheel Track Test and in contrary to the results of the previous studies, average rut depth for specimens prepared with bitumen 60-70 grade is more than bitumen 85-100 grade prepared specimens. The reason will be for used bitumen's properties, especially penetration grade, softening point, ductility, and the cohesion of bitumen.

5.3 The results of rut depth model using wheel track tester

- In this model, the positive coefficient for vertical deformation (V) indicated that as the vertical deformation increases, there is an increase in rut depth and a decrease in rutting resistance.

- The negative coefficient for Marshall Stability (M) in this model shows that rut depth has an inverse relationship with it, and indicates that as the Marshall Stability increases, the rut depth decreases. As a result, rutting resistance and Marshall Stability have a directs relationship.

- Indirect tensile strength coefficient is positive in the developed model. So specimens with higher IDT strength have more rut depth and low rut resistance.

- In contrary to Anderson's results, VMA was not selected as an independent variable for the final equation. Least squares regression with VMA included demonstrated coefficient was not statistically significant.

- Also in this research, the other parameters of Marshall that considered as predictor variables were not selected as an independent variable or determination coefficient for regression model, that include Marshall Flow (F), Marshall Ratio (M/F), Air Voids in Compacted Asphalt Mixture (A), Voids in Mineral Aggregate (V1), and Voids Filled with Asphalt Cement (V2).

Using developed model with a correlation coefficient $\left(\mathrm{R}^{2}=0.962\right)$, the rut depth can be estimated simultaneously during specimen preparation for determining $\mathrm{OBC}$ and evaluate rutting index before preparation, so a considerable save will be held in time and costs.

\section{ACKNOWLEDGEMENTS}

Author wish to thank the Asphalt mixture and Bitumen Research Center (ABRC) of Iran University of Science and Technology (IUST) for helping to perform the experiments.

\section{FOOTNOTE}

1. Laboratoire Central des Ponts et Chaussé

2. National Cooperative Highway Research Program (NCHRP)

3. Federal Highway Administration (FHA)

4. Federal Aviation Administration (FAA)

5. Hot Mix Asphalt (HMA)

6. Asphalt Pavement Analyze (APA)

7. Repeated Shear Testing at Constant Height (RSTCH)

8. Statistical Package for the Social Sciences (SPSS)

9. Artificial Neural Network (ANN) 


\section{References:}

(TRI), Transportation Research Institute. 2010. "Experimental Study of Gradation Type and Voids Effect on Bleeding and Rutting in Asphalt Concrete in Iran, Tehran, Iran." Transportation Research Institute.

Al-Khateeb, G.G., Al-Suleiman Obaidat, T.I., Khedaywi, T.S. and Elayan, M.S., 2018. Studying rutting performance of Superpave asphalt mixtures using unconfined dynamic creep and simple performance tests. Road Materials and Pavement Design, 19(2), pp.315-333.

Anderson, R.M., 2002. Relationship of Superpave gyratory compaction properties to HMA rutting behavior (Vol. 478). Transportation Research Board.

Anderson, R.M., Christensen, D.W. and Bonaquist, R., 2003. Estimating the rutting potential of asphalt mixtures using Superpave gyratory compaction properties and indirect tensile strength (with discussion). Journal of the Association of Asphalt Paving Technologists, 72 .

Barman, M., Imran, S.A., Nazari, M., Commuri, S. and Zaman, M., 2018. Use of Intelligent Compaction in Detecting and Remediating Under-Compacted Spots During Compaction of Asphalt Layers. In Civil Infrastructures Confronting Severe Weathers and Climate Changes Conference, Springer, Cham, pp. 131-141.

Code, Iran Highway Asphalt Paving. 2011. Vice Presidency for Strategic Planning and Supervision. The Ministry of Roads and Urban Development, Asphalt Institute of Iran.

Du, Y., Chen, J., Han, Z. and Liu, W., 2018. A review on solutions for improving rutting resistance of asphalt pavement and test methods. Construction and Building Materials, 168, pp.893-905.

Gong, H., Sun, Y., Hu, W. and Huang, B., 2019. Neural networks for fatigue cracking prediction using outputs from pavement mechanistic-empirical design. International Journal of Pavement Engineering, pp.1-11.

Gu, F., Luo, X., Zhang, Y., Chen, Y., Luo, R. and Lytton, R.L., 2018. Prediction of geogrid-reinforced flexible pavement performance using artificial neural network approach. Road Materials and Pavement Design, 19(5), pp.1147-1163.

Inzerillo, L., Di Mino, G., Bressi, S., Di Paola, F. and Noto, S., 1995. Image Based Modeling Technique for Pavement Distress Surveys: a Specific Application to Rutting. International Journal of Engineering and Technology, 16(5), pp.1-9.

Kaya, O., Garg, N., Ceylan, H. and Kim, S., 2018. Development of Artificial Neural Networks Based Predictive Models for Dynamic Modulus of Airfield Pavement Asphalt Mixtures. In International Conference on Transportation and Development 2018: Airfield and Highway Pavements, Reston, VA: American Society of Civil Engineers, pp. 1-7.

Liao, G., Wang, S. and Shi, Q., 2018. Enhancing anti-rutting performance of asphalt pavement by dispersing shear stresses within asphalt layers. Road Materials and Pavement Design, 19(2), pp.453469.

Mamlouk, M., Vinayakamurthy, M., Underwood, B.S. and Kaloush, K.E., 2018. Effects of the International Roughness Index and Rut
Depth on Crash Rates. Transportation Research Record, 2672(40), pp.418-429.

Mansourian, A., Ghanizadeh, A.R. and Golchin, B., 2019. Modeling of Resilient Modulus of Asphalt Concrete Containing Reclaimed Asphalt Pavement using Feed-Forward and Generalized Regression Neural Networks. Journal of Rehabilitation in Civil Engineering, 7(1), pp.21-41.

McGarvey, K., Panko, M., Hurt, C., Mehta, Y. and Sukumaran, B., 2010. Use of the Superpave Gyratory Compactor as a Predictor of Field Performance of Unbound Material. In 2010 FAA Worldwide Airport Technology Transfer ConferenceFederal Aviation AdministrationAmerican Association of Airport Executives.

Parsons, T.A., Kazmee, H. and Garg, N., 2017. Sensitivity Analysis of Rut Depth to Longitudinal Measurement Location in Accelerated Pavement Testing with a Heavy Vehicle Simulator-Airfield. In Airfield and Highway Pavements 2017 (pp. 115-126).

Radhakrishnan, V., Dudipala, R.R., Maity, A. and Sudhakar Reddy, K., 2019. Evaluation of rutting potential of asphalts using resilient modulus test parameters. Road Materials and Pavement Design, 20(1), pp.20-35.

Shafabakhsh, G.A., Divandari, H. and Sajadi, S.R., 2018. Evaluation of Optimum Content of Rice Husk Ash to Improve the Hot Asphalt Concrete Performance. International Journal of Engineering and Technology, Vol. 7, No. 4.20, pp. 338-346, DOI: 10.14419/ijet.v7i4.20.26131.

Wang, D., Falchetto, A.C., Goeke, M., Wang, W., Li, T. and Wistuba, M.P., 2017. Influence of computation algorithm on the accuracy of rut depth measurement. Journal of traffic and transportation engineering (English edition), 4(2), pp.156-164.

Yi, W., Wang, Y.H. and Zhou, R., 2011. Study on Rutting of Asphalt Pavement. In Advanced Materials Research, Trans Tech Publications.Vol. 163, pp. 1096-1099.

Zaniewski, J.P. and Srinivasan, G,. 2004. Evaluation of indirect tensile strength to identify asphalt concrete rutting potential. Asphalt Technology Program, Department of Civil and Environmental Engineering, West Virginia University, Performed in Cooperation with the US Department of Transportation-Federal Highway Administration.

Zhang, W., Shen, S., Wu, S., Chen, X., Xue, J. and Mohammad, L.N., 2019. Effects of In-Place Volumetric Properties on Field Rutting and Cracking Performance of Asphalt Pavement. Journal of Materials in Civil Engineering, 31(8), p.04019150.

Ziari, H. and Divandari, H., 2013. Presenting asphalt mixtures flow number prediction model using gyratory curves. International Journal of Civil Engineering, 11 (2), pp. 125-133.

Ziari, H., Divandari, H., Behbahan, H. and Ameri, M., 2012. Developing a Forecasting Model for Asphalt Rutting Potential Using Gyratory Compactor Parameters. Life Science Journal, 9 (4), pp. 4140-4149.

Ziari, H., Divandari, H., Hajiloo, M. and Amini, A., 2019. Investigating the effect of amorphous carbon powder on the moisture sensitivity, fatigue performance and rutting resistance of rubberized asphalt concrete mixtures. Construction and Building Materials, Vol. 217, pp. 62-72, DOI: 10.1016/j.conbuildmat.2019.05.039. 